\title{
MOVIMENTO DO HERBICIDA IMAZETAPIR EM UM \\ NEOSSOLO QUARTZARÊNICO TÍPICO E EM UM \\ LATOSSOLO DE TEXTURA MÉDIA DAS NASCENTES DO RIO ARAGUAIA, MUNICÍPIO DE MINEIROS (GO)
}

\author{
MARCO ANTONIO FERREIRA GOMES* \\ ANDERSON SOARES PEREIRA** \\ SÔNIA CLÁUDIA DO NASCIMENTO DE QUEIROZ*** \\ VERA LÚCIA FERRACINI ${ }^{\star \star \star *}$ \\ ISABEL CRISTINA SALES FONTES JARDIM***** \\ MÁRCIA MARIA DE PAULA****** \\ ALCEBÍADES DIOGO ${ }^{\star \star \star \star \star \star *}$
}

\begin{abstract}
O movimento do herbicida imazetapir foi analisado em Neossolo Quartzarênico Órtico típico (RQo) e em Latossolo VermelhoAmarelo textura média (LVAq), sob cultivo de soja, tipicamente representativos das áreas de recarga do aqüífero Guarani na região das nascentes do rio Araguaia, GO/MT, tendo como fatores influenciadores a condutividade hidráulica $(K)$, o teor de carbono orgânico (CO) e o teor de argila (TAr). Corroboram com a condutividade hidráulica os fatores porosidade total $\left(n_{t}\right)$, microporosidade $\left(\mathrm{n}_{\mathrm{mi}}\right)$, macroporosidade $\left(\mathrm{n}_{\mathrm{ma}}\right)$ densidade do solo (Ds) e capacidade de campo (Cc). O presente estudo foi realizado em colunas de solos indeformados, com aplicação do produto comercial (Pivot) contendo o herbicida em discussão. Esses parâmetros evidenciaram certa influência na movimentação vertical do herbicida imazetapir, aliados à sua condição aniônica na faixa de $\mathrm{pH}$ entre 5 e 8, típica dos solos em questão. Observouse, por exemplo, valores de $\mathrm{K}$ com diferença significativa entre os dois solos, sendo superior no RQo, além de relação inversa entre teores de $\mathrm{CO}$ e de $\mathrm{TAr}$ e os valores de $\mathrm{K}$ dos dois solos, indicando serem aqueles parâmetros inibidores ou pouco favoráveis ao deslocamento do imazetapir no perfil do solo, principalmente por meio das pontes de hidrogênio e interações hidrofóbicas pela matéria orgânica. Os resultados aqui obtidos visam subsidiar estudos de avaliação de risco ambiental, sobretudo para água subterrânea, a partir de áreas de recarga de aqüíferos, naturalmente frágeis, com ênfase para o aqüífero Guarani.
\end{abstract}

PALAVRAS-CHAVE: NEOSSOLO QUARTZARÊNICO ÓRTICO; LATOSSOLO VERMELHO-AMARELO; IMAZETAPIR; CONDUTIVIDADE HIDRÁULICA; ÁGUA SUBTERRÂNEA; HERBICIDA.

* Geólogo, D.Sc. em Solos e Nutrição de Plantas, pesquisador da Embrapa Meio Ambiente, Jaguariúna, SP (e-mail: gomes@cnpma.embrapa.br).

** Engenheiro Agrônomo, D.Sc. em Irrigação e Drenagem, pesquisador da Embrapa Meio Ambiente, Jaguariúna, SP (e-mail: anderson@cnpma.embrapa.br).

*** Química, D.Sc. em Ciência, pesquisadora da Embrapa Meio Ambiente, Jaguariúna, SP (e-mail: sonia@cnpma.embrapa.br).

**** Química, D.Sc. em Química Orgânica, pesquisadora da Embrapa Meio Ambiente, Jaguariúna, SP (e-mail: veraf@cnpma.embrapa.br).

**** Química, Doutora em Ciência, Professora Titular, Departamento de Química Analítica, Instituto de Química, Universidade Estadual de Campinas (UNICAMP), Campinas, SP (e-mail: icsfj@iqm. unicamp.br)

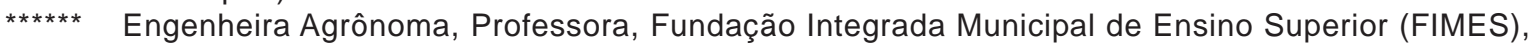
Mineiros-GO Extensionista da SEAGRO - Mineiros, GO (e-mail: marcia@fimes.edu.br).

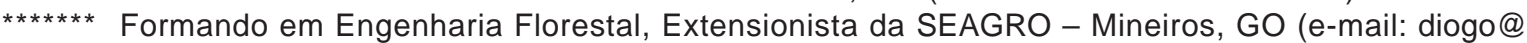
agenciarural.go.gov.br). 


\section{INTRODUÇÃO}

O destino de agrotóxicos no ambiente, sobretudo na água subterrânea, tem sido o foco de várias abordagens, uma vez que esses mananciais se tornaram alvo preferencial de interesses, principalmente comerciais, devido à escassez de água superficial sob o aspecto qualitativo e à própria pressão para cobrança desse bem vital. Nesse contexto, a atividade agrícola tradicional passou a assumir responsabilidade sem precedentes por exigir quantidade considerável de agrotóxicos, sejam eles herbicidas, inseticidas, fungicidas, nematicidas, acaricidas ou formicidas. Assim, o uso desses produtos requer orientação mais adequada, na qual devem ser observadas suas principais características físico-químicas, bem como as características físicas, químicas e biológicas do solo em que serão aplicados.

O herbicida imazetapir, objeto de investigação do presente trabalho, foi selecionado para estudo em função de seu uso intensivo na cultura de soja em área de recarga do aqüífero Guarani na região das nascentes do rio Araguaia, GO/MT, e principalmente, por exibir alto potencial de lixiviação pelos índices de GUS (GUSTAFSON, 1989) e LIX (SPADOTTO, 2002), o que o destaca como produto com risco de contaminação da água subterrânea (DORES e DE-LAMONICA-FREIRE, 2001).

Quimicamente o imazetapir é um ácido múltiplo, pertencente ao grupo químico das imidazolinonas, com constante de ionização ácida (pKa) igual a 2,2 e ionização básica (pKb) igual a 3,9; apresenta Koc igual a $10 \mathrm{~cm}^{3} / \mathrm{g}$ e meia-vida $\left(\mathrm{T}_{1 / 2}\right)$ no solo de 90 dias. Outro fator importante que torna o imazetapir com potencial para lixiviar envolve sua solubilidade em água cujo valor é de 1.400 mg/L (VonHERTWIG, 1983; DORES e DE-LAMONICA-FREIRE, 2001; WSSA, 2002).

O comportamento das imidazolinonas no solo é fortemente afetado pelo $\mathrm{pH}$ (LOUX e REESE, 1992; OLIVEIRA, 1998), teores de carbono orgânico (GOETZ et al., 1986; CHE et al., 1992; OLIVEIRA, 1998), textura (LOUX, LIEBL e SLIFE, 1989), mineralogia (CHE et al., 1992; REGITANO et al., 1997; OLIVEIRA, 1998; FERREIRA et al., 2002) e retenção de água pelo solo (GOETZ, LIEBL e SLIFE, 1986). A mobilidade e a eficiência geralmente decrescem com o aumento da sorção pelos colóides do solo.

Em níveis de $\mathrm{pH}$ entre 5 e 8, faixa em que se encontram os dois solos selecionados para este estudo, a sorção do imazetapir sofre redução devido ao predomínio de sua forma aniônica, condição que favorece o processo de lixiviação. No entanto, esse parâmetro e o conteúdo de argila (Tar) são mais eficientes nos processos relacionados à sorção de agrotóxicos polares ou ionizáveis (GREEN e KARICHHOFF, 1990).

Para NICHOLLS (1991) a adsorção de compostos não-ionizáveis está relacionada principalmente ao teor de matéria orgânica dos solos. Nos processos de adsorção, que envolvem a matéria orgânica, seu teor e sua superfície específica são parâmetros determinantes. Esses normalmente variam nos solos e são maiores em solos argilosos e menores em solos arenosos. Tal fato pode representar um dos motivos pelos quais o imazetapir se desloca mais facilmente em solos do tipo areia e/ou bastante arenosos.

Nos solos arenosos, tipicamente no Neossolo Quartzarênico Órtico típico (Rqo), existe alta relação macro/microporos, dado o elevado grau de arredondamento dos grãos de quartzo que o compõe. Tal condição favorece a percolação mais rápida da água, traduzida pela alta condutividade hidráulica desse solo (K) que, aliada ao seu baixo teor de argila (Tar) e baixo teor de matéria orgânica (CO), contribuem para a intensificação do processo de lixiviação.

No presente trabalho avaliou-se o movimento do herbicida imazetapir em dois solos distintos, representativos da área de recarga do aqüífero Guarani no Brasil, tendo como principais parâmetros influenciadores, a condutividade hidráulica (K), o teor de carbono orgânico (CO) e o teor de argila (TAr).

\section{MATERIAL E MÉTODOS}

\section{1 ÁREA}

Selecionou-se, como unidade de estudo, uma porção de área localizada nas nascentes do rio Araguaia, no Estado de Goiás, também conhecida por Depressão do Araguaia (GOMES, FILIZOLAe 
SPADOTTO, 2006), cujas coordenadas situam-se entre $17^{\circ} 48^{\prime} 25.56104 " \mathrm{~S}$ e $18^{\circ} 02^{\prime} 23.67782^{\prime \prime S}$ e $59^{\circ} 00^{\prime} 00.06399^{\prime \prime W}$ e 59¹1'29.36042"W. Esse local, reconhecido como área de recarga direta do aqüífero Guarani, é ocupado intensivamente por soja, sendo vulnerável sob o ponto de vista do risco de contaminação da água subterrânea.

Os solos representativos das áreas de recarga do aqüífero Guarani, localizadas nas nascentes do rio Araguaia (GO/MT), são o Latossolo Vermelho-Amarelo textura média e o Neossolo Quartzarênico Órtico (EMBRAPA, 2006; GOMES et al., 2007). As principais características físicas de cada solo de interesse para o presente trabalho, até a profundidade de $80 \mathrm{~cm}$, estão contidas na Tabela 1. Esses solos foram coletados em locais circunvizinhos às amostras indeformadas, por meio de tubos e submetidas à avaliação da lixiviação do imazetapir.

Os valores de macro e microporosidade foram determinados no laboratório da Embrapa Meio Ambiente pelo método do funil (BOUMA, 1973) e os de condutividade hidráulica (K) pelo método de campo ou direto (FERNANDES et al., 1983). Os demais parâmetros foram obtidos a partir de publicações, conforme consta do rodapé da Tabela 1.

\subsection{COLETA DE SOLO EM COLUNAS, INSTALAÇÃO DAS COLUNAS NO LISÍMETRO E COLETA DAÁGUA PERCOLADA NO LISÍMETRO APÓS AAPLICAÇÃO DO IMAZETAPIR}

Oito colunas de solos, sendo quatro de RQo e quatro de LVAq, foram obtidas na Fazenda Três Irmãos, município de Mineiros/GO em área de recarga do aqüífero Guarani, por meio de tubos de poli cloreto de vinila (PVC) de $15 \mathrm{~cm}$ de diâmetro por $80 \mathrm{~cm}$ de comprimento. Os tubos foram introduzidos no solo, mecanicamente, evitando-se a deformação das amostras para obter a melhor representatividade do perfil original do solo. O procedimento mecânico de introdução dos tubos no solo consistiu de aplicação de golpes sobre tábua colocada na parte superior (boca) dos respectivos tubos para proteger suas bordas. Todo o material coletado foi transferido e instalado no lisímetro do Laboratório de Qualidade de Solos (LQS) da Embrapa Meio Ambiente, em Jaguariúna/SP. Os solos contidos nos tubos foram submetidos à saturação por capilaridade, o que ocorreu após uma semana. Os tubos foram isolados sem qualquer contato com umidade externa, durante 48 horas, para a obtenção da capacidade de campo. Em seguida, foram adicionados $300 \mathrm{~mL}$ de água, diariamente, em cada tubo até que o volume coletado permanecesse constante ( 15 dias). Após a instalação dos tubos, o imazetapir foi aplicado na parte superior de cada tubo (superfície do solo) em concentração equivalente à dosagem de 1,0 L/ha do produto comercial contendo $100 \mathrm{~g} \mathrm{~L}^{-1}$ do ingrediente ativo (i.a.).

As colunas de solo foram expostas às condições naturais, com drenagem livre, de acordo com o regime pluviométrico local. Efetuou-se coleta de água para cada tubo no período de 08/02/2005 a 26/11/2006, totalizando 8 coletas (Quadro 1). Retirou-se alíquota de $100 \mathrm{~mL}$ de cada coluna que foi mantida congelada $\left(-18^{\circ} \mathrm{C}\right.$ ) até a realização da análise cromatográfica (MATALLO et al., 2005; GOMES, et al., 2006).

Adotou-se delineamento experimental inteiramente casualizado, com 8 tratamentos referentes a cada um dos tubos, com 8 repetições por tratamento, relativas aos dias de coleta. Empregou-se o teste t para avaliar a significância dos resultados, conforme descrito por GOMES (1985).

\subsection{PREPARO DAS AMOSTRAS E ANÁLISE CROMATOGRÁFICA}

As amostras coletadas foram filtradas em filtro de fibra de vidro de $7 \mu \mathrm{m}$ e membrana de fluoreto de polivinilideno (PVDF) de 0,22 $\mu \mathrm{m}$ para a remoção de eventual material particulado e colóide presente nos eluatos.

As análises do imazetapir foram efetuadas segundo o método de extração em fase sólida (EFS), com o uso de cartuchos lab-made C8 imobilizado (VIGNA et al., 2006). Utilizou-se cromatógrafo a líquido, Shimadzu mod. LC 2010, com bomba de alta pressão modelo LC - 10AT, detector 
espectrométrico Ultra-Violeta/Visível (UV/Vis), de comprimento de onda variável entre 190 a $900 \mathrm{~nm}$ e injetor automático (SIL 10AF) com volume de injeção de $10 \mu \mathrm{L}$. Obteve-se a separação com coluna de fase reversa RP-18 Nova-Pak $150 \times 4 \mathrm{~mm}$ (partículas com $5 \mu \mathrm{m}$ de diâmetro) protegida por pré-coluna RP-18 Shimpack. Empregou-se como fase móvel água: acetonitrila (1:1) pH 3,0 num fluxo de $1,0 \mathrm{~mL}$ min $^{-1}$ (JARDIM et al., 2008).

A curva de calibração foi obtida com soluções em metanol de imazetapir grau analítico (99,9\%), nas concentrações de 400,600, 900, 1.500, 3000 e $4500 \mu \mathrm{g} \mathrm{mL}^{-1}$, conforme a Figura 1.

\section{FIGURA 1 - CURVA ANALITICA, OBTIDA COM OS PONTOS 1, 2, 3, 5, 10 E 15 X O LIMITE DE QUANTIFICAÇÃO (LOQ) DO INSTRUMENTO PARA O HERBICIDA IMAZETAPIR}

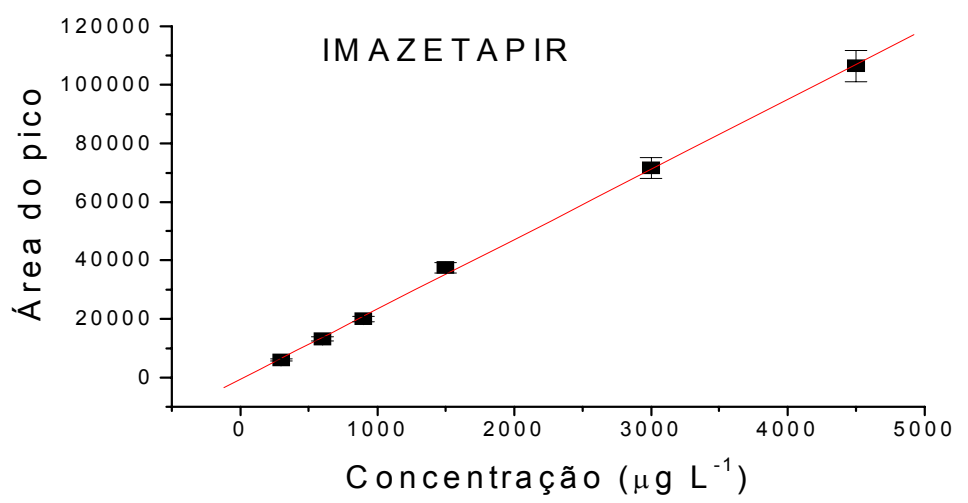

3 RESULTADOS E DISCUSSÃO

A Tabela 1 mostra diferença significativa entre os valores de carbono orgânico (CO), condutividade hidráulica (K) e teor de argila (TAr) dos dois solos, o que conduz à hipótese de que os mesmos devem ser os principais agentes influenciadores no processo de movimentação do imazetapir no solo. Os valores de macroporosidade, relação macro/microporos e porosidade total apresentaram relação direta com os valores de condutividade hidráulica, constituindo fatores influentes nos valores mais elevados desse parâmentro. Já a densidade do solo mostrou relação inversa, o que também reforça a influência desse fator na condutividade hidráulica, uma vez que baixos valores de densidade contribuem para o aumento do fluxo de água no perfil do solo.

TABELA 1 - CARACTERIZAÇÃO FíSICA REPRESENTATIVA DOS SOLOS LVAdq E RQo (NÃO-CULTIVADOS) DAS ÁREAS DE RECARGA DO AQÜÍFERO GUARANI NA REGIÃO DAS NASCENTES DO RIO ARAGUAIA (FAZENDA TRÊS IRMÃOS), MUNICÍPIO DE MINEIROS-GO, CONSIDERANDO AMOSTRAS OBTIDAS PRÓXIMO AOS LOCAIS DE COLETA DOS TUBOS, REFERENTES À PROFUNDIDADE DE $0-60 \mathrm{~cm}$

\begin{tabular}{lccccccccc}
\hline Solo & $\begin{array}{c}\mathrm{CO} \\
\left(\mathrm{g} \mathrm{Kg}^{-1}\right)\end{array}$ & $\begin{array}{c}\text { Macropo- } \\
\text { rosidade } \\
\left(\mathrm{m}^{3} \mathrm{~m}^{-3}\right)\end{array}$ & $\begin{array}{c}\text { Micropo- } \\
\text { rosidade } \\
\left(\mathrm{m}^{3} \mathrm{~m}^{-3}\right)\end{array}$ & $\begin{array}{c}\text { Relação } \\
\text { Macro/ } \\
\text { micro- } \\
\text { poros }\end{array}$ & $\begin{array}{c}\text { Porosidade } \\
\text { Total }-\mathrm{n}_{\mathrm{t}} \\
\left(\mathrm{m}^{3} \mathrm{~m}^{-3}\right)\end{array}$ & $\begin{array}{c}\mathrm{K}^{3} \\
\left(\mathrm{~cm} \mathrm{~h}^{-1}\right)\end{array}$ & $\begin{array}{c}\mathrm{Ds} \\
\left(\mathrm{mg} \mathrm{m}^{-3}\right)\end{array}$ & $\begin{array}{c}\mathrm{CC} \\
\left(\mathrm{dm}^{3} \mathrm{dm}^{-3}\right)\end{array}$ & $\begin{array}{c}\text { Argila } \\
\left(\mathrm{g} \mathrm{kg}^{-1}\right)\end{array}$ \\
\hline LVAdq & $4,15 \mathrm{a}$ & $0,22 \mathrm{a}$ & $0,43 \mathrm{a}$ & $0,51 \mathrm{a}$ & $0,94 \mathrm{a}$ & $49,53 \mathrm{~b}$ & $1,23 \mathrm{a}$ & $0,27 \mathrm{a}$ & $177,25 \mathrm{a}$ \\
RQO & $2,86 \mathrm{~b}$ & $0,25 \mathrm{~b}$ & $0,40 \mathrm{a}$ & $0,62 \mathrm{~b}$ & $1,02 \mathrm{~b}$ & $55,61 \mathrm{a}$ & $1,20 \mathrm{~b}$ & $0,25 \mathrm{~b}$ & $90,13 \mathrm{~b}$ \\
\hline
\end{tabular}

CO = Carbono orgânico; Ds = Densidade do solo; CC = Capacidade de campo e argila (EMBRAPA, 2002; EMBRAPA, 2007). 1, 2, 3 Determinados para este trabalho (BOUMA, 1973; FERNANDES at al., 1983).

Valores seguidos pela mesma letra, na vertical, não diferem entre si a $5 \%$, pelo teste $t$. 
A Figura 2 ilustra as tendências de variação da quantidade de imazetapir $(\mu \mathrm{g})$ em função dos parâmetros carbono orgânico (CO), condutividade hidráulica (K) e teor de argila (TAr) dos dois solos estudados.

Os gráficos $A$ e $C$ evidenciam relação inversa com o gráfico $B$, ficando claro que o maior deslocamento do imazetapir é definido não apenas pela maior condutividade hidráulica mas, também, pelos menores teores de carbono orgânico e de argila do Neossolo Quartzarênico Órtico (RQo).

\section{FIGURA 2 - QUANTIDADE DE IMAZETAPIR $(\mu \mathrm{g})$ NOS ELUATOS COLETADOS EM FUNÇÃO DO CARBONO ORGÂNICO (A); CONDUTIVIDADE HIDRÁULICA (B) E TEOR DE ARGILA (C) PARA OS SOLOS LATOSSOLO VERMELHO-AMARELO DISTRÓFICO PSAMÍTICO (LVAdq) E NEOSSOLO QUARTZARÊNICO ÓRTICO (RQO)}

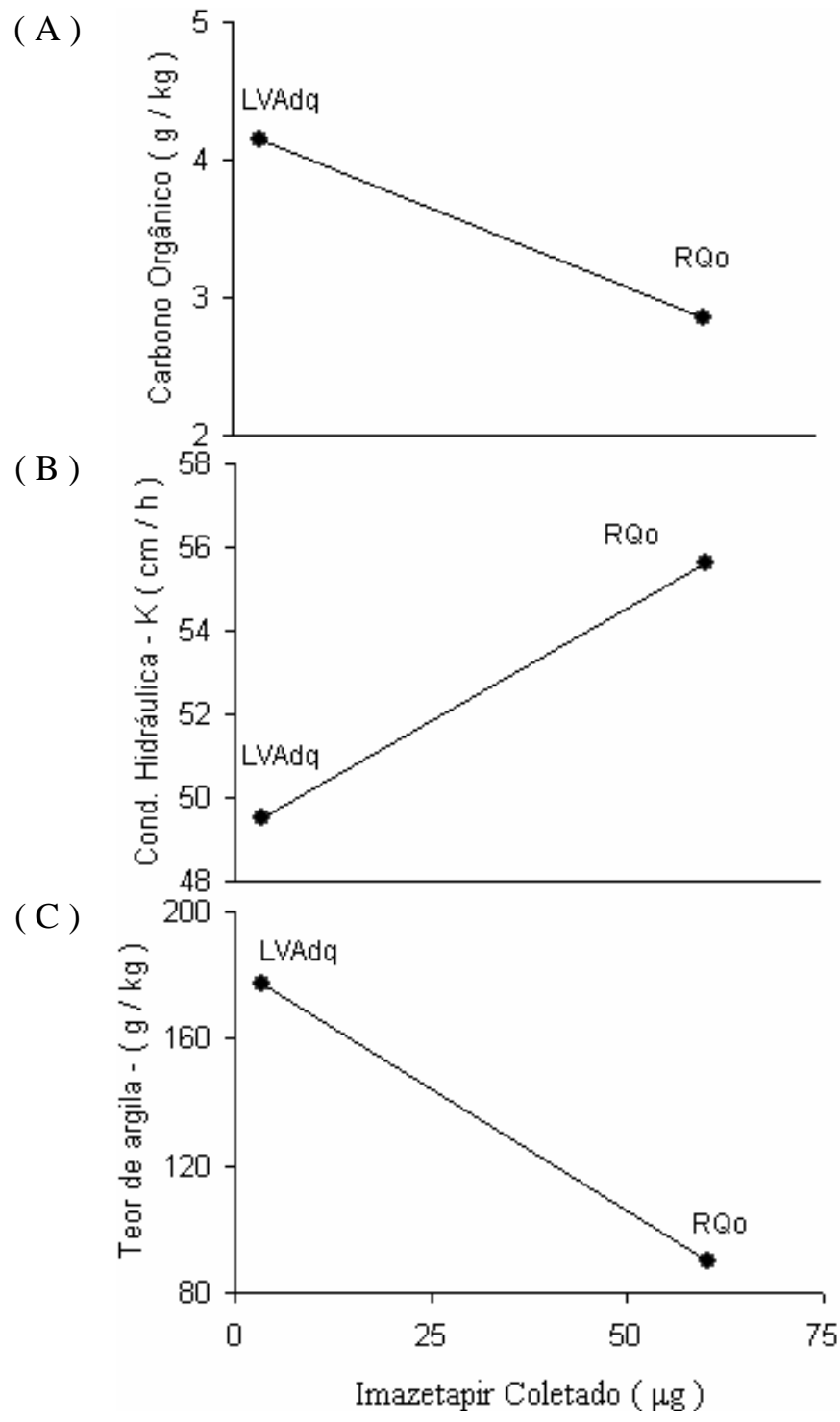

Os resultados obtidos, expressos no Quadro 1 em relação à presença de imazetapir nos eluatos, correspondem à média detectada para cada tipo de solo em cada época de coleta durante 21 meses, no período compreendido entre 08/02/2005 e 16/03/2006, totalizando 8 coletas com freqüência trimestral. 


\section{QUADRO 1 - QUANTIDADE DE IMAZETAPIR ( $\mu \mathrm{g}$ ) NOS ELUATOS COLETADOS TRIMESTRALMENTE DURANTE O PERÍODO DE 08/02/2005 A 16/03/2006}

\begin{tabular}{|c|c|c|c|c|c|c|c|c|}
\hline \multirow{3}{*}{$\begin{array}{l}\text { Datas de } \\
\text { coleta }\end{array}$} & \multicolumn{8}{|c|}{ Imazetapir $(\mu \mathrm{q})$} \\
\hline & \multicolumn{4}{|c|}{ LVA dq } & \multicolumn{4}{|c|}{ RQo } \\
\hline & Tubo 1 & Tubo 2 & Tubo 3 & Tubo 4 & Tubo 5 & Tubo 6 & Tubo 7 & Tubo 8 \\
\hline $08 / 02 / 05$ & 3,1 & 2,8 & 2,3 & 2,0 & 4,8 & 4,0 & 5,2 & 4,6 \\
\hline $17 / 05 / 05$ & 2,6 & 1,5 & 1,1 & 1,8 & 18,2 & 24,5 & 29,3 & 30,4 \\
\hline $28 / 08 / 05$ & 2,2 & 2,0 & 1,7 & 1,9 & 18,3 & 22,6 & 26,4 & 20,5 \\
\hline $06 / 11 / 05$ & 1,4 & 1,1 & 2,1 & 1,6 & 34,9 & 52,2 & 47,6 & 38,7 \\
\hline $15 / 02 / 05$ & 1,9 & 2,6 & 3,3 & 3,1 & 100,1 & 125,4 & 105,2 & 129,6 \\
\hline $25 / 05 / 06$ & 2,7 & 2,9 & 3,4 & 4,5 & 75,3 & 82,9 & 102,9 & 93,5 \\
\hline 19/08/06 & 4,8 & 3,7 & 4,6 & 5,0 & 83,5 & 53,7 & 67,9 & 77,1 \\
\hline $26 / 11 / 06$ & 7,5 & 9,1 & 10,2 & 7,9 & 102,7 & 120,1 & 116,8 & 111,4 \\
\hline TOTAL & 26,2 & 25,7 & 28,7 & 27,8 & 437,8 & 485,4 & 501,3 & 505,8 \\
\hline Média & $3,28 a$ & $3,21 a$ & $3,59 a$ & $3,48 a$ & $54,73 b$ & $60,68 b$ & $62,66 b$ & $63,23 b$ \\
\hline $\begin{array}{c}\text { Média (tipo } \\
\text { de solo) }\end{array}$ & \multicolumn{4}{|c|}{$3,39 a$} & \multicolumn{4}{|c|}{$60,33 b$} \\
\hline
\end{tabular}

"Valores seguidos pela mesma letra, na horizontal, não diferem entre si a 5\% pelo teste t.

Conforme se observa (Quadro 1) houve diferença significativa entre as quantidades médias de imazetapir lixiviado nos dois solos. A quantidade média total do mesmo no Neossolo Quartzarênico Órtico típico (RQo) mostrou-se cerca de 17,8 vezes maior do que no Latossolo Vermelho-Amarelo Distrófico psamítico (LVAdq) .

Acrescentam-se às informações obtidas para o RQo, a análise do potencial de lixiviação do imazetapir de acordo com o índice GUS, proposto por GUSTAFSON (1989), que o classifica como lixiviável e cuja característica está estreitamente relacionada com seu coeficiente de lipofilicidade (Kow). A baixa adsortividade do imazetapir, aliada à sua alta persistência no solo, deve ser o principal fator responsável pela sua maior mobilidade no RQo. Outro índice de lixiviação adotado, conforme SPADOTTO, GOMES e HORNSBY (2002), foi o LIX que no intervaldo de 0 a 1 mostra o imazetapir com valor de 0,93 e confirma seu caráter de composto muito lixiviável. Outro índice adotado na avaliação do imazetapir foi o Fator de Atenuação (Atennuation Factor), cujo valor de 0,35 obtido no Neossolo Quartarênico órtico (RQo), considerando a média obtida na faixa de profundidade de 0-60 cm, o classifica como sendo um produto com potencial de lixiviação muito alto, segundo SPADOTTO, GOMES e HORNSBY (2002). A Tabela 2 sintetiza algumas características importantes do imazetapir na avaliação de sua mobilidade no perfil do solo.

\section{TABELA 2 - COEFICIENTE DE ADSORÇÃO PELA MATÉRIA ORGÂNICA, PERSISTÊNCIA, ÍNDICES DE GUS, LIX, AF E KoW PARA O IMAZETAPIR}

\begin{tabular}{ccccccc} 
Herbicida & $\mathrm{KOC}_{(\mathrm{mL} / \mathrm{g})^{*}}$ & $\mathrm{t}_{12}$ (dias) $^{*}$ & GUS $^{*}$ & LIX & AF & $\mathrm{KoW}^{*}$ \\
\hline Imazetapir & 10 & $30-90$ & 5,9 & 0,93 & 0,35 & 31 \\
\hline
\end{tabular}

* DORES e DE-LAMONICA-FREIRE (2001).

** GUSTAFSON (1989).

LIX (baseado em SPADOTTO, GOMES e HORNSBY (2002).

$\mathrm{AF}=$ Attenuation Factor (baseado em SPADOTTO, GOMES e HORNSBY, 2002).

Os resultados do presente trabalho mostram a necessidade de se aprofundar os estudos em relação à lixiviação do herbicida imazetapir em solos tropicais, sobretudo em solos arenosos, a exemplo dos que ocorrem na região das nascentes do rio Araguaia (GO/MT), representativos das áreas de recarga direta do aqüífero Guarani no Brasil. 


\title{
4 CONCLUSÃO
}

O imazetapir aplicado no Neossolo Quartzarênico Órtico e no Latossolo Vermelho-Amarelo Distrófico psamítico apresentou boa lixiviação através da camada de $80 \mathrm{~cm}$, mas seu potencial de lixiviação no primeiro é cerca de 17,8 vezes maior em relação ao segundo solo.

Os teores mais baixos de matéria orgânica e de argila do Neossolo Quartzarênico, que influenciam os valores de condutividade hidráulica, parecem ser os parâmetros determinantes na lixiviação mais elevada do imazetapir nesse solo, comparado ao Latossolo Vermelho-Amarelo Distrófico psamítico.

A macroporosidade, a porosidade total e a relação macro/microporos estão diretamente vinculadas aos valores de condutividade hidráulica, evidenciando que valores mais elevados daqueles contribuem para taxas mais elevadas dessa.

A densidade do solo apresentou relação inversa com a condutividade hidráulica, com menor valor no RQo, mostrando-se como parâmetro adequado para explicar a taxa de condutividade hidráulica mais elevada nesse solo em comparação ao LVAdq.

Nos dois tipos de solo, a lixiviação do imazetapir foi inversamente proporcional aos teores de carbono orgânico e argila e diretamente proporcional à condutividade hidráulica.

\begin{abstract}
MOVEMENT OF THE IMAZETAPHYR HERBICIDE IN TYPIC QUARTZIPSAMMENT AND QUARTZIPSAMMENTIC HAPLORTOX SOILS OF THE ARAGUAIA RIVER SOURCES, MINEIROS-GO (BRAZIL)

The movement of the herbicide imazetaphyr was analysed in Typic Quartzipsamment and Quartzipsammentic Haplortox soils, under soy cultivation, of the recharge areas of the Guarani aquifer in the regions of Araguaia river source in Goias and Mato Grosso so Sul - Brazil, being main factors in this movement the hydraulic conductivity $(\mathrm{K})$, organic carbon content $(\mathrm{OC})$ and clay content $(\mathrm{CC})$. The factors total pororsity $\left(\mathrm{n}_{\mathrm{t}}\right)$, microposrosity $\left(n_{m i}\right)$, macroporosity $\left(n_{m a}\right)$, soil density (Ds) and field capacity (FC) corroborate with the hydraulic conductivity. The experiment was developed in columns soils whit preserved structure, with application of the commercial product (Pivot) containing the herbicide in discussion. These parameters show likely influence on the vertical movement of the imazetaphir herbicide connected to its anionic condition, mainly in $\mathrm{pH}$ between 5 and 8 , typical of the soils in question. Were observed, for example, a significant difference between $\mathrm{K}$ values of the two soils, being higher to Typic Quartzipsamment, besides an inverse relation between carbon content $(\mathrm{OC})$ and clay content $(\mathrm{CC})$ values and hydraulic conductivity $(\mathrm{K})$ values of the two soils, showing to be inhibitors parameters in the movement of the imazetaphir in soil profile, mainly by hydrogen bonds and hydrophobic interactions by organic matter. The results obtained in this work aim to subside assessment environmental risks, over all groundwater, considering aquifers recharge areas, naturally fragile, whit emphasis to the Guarani aquifer.
\end{abstract}

KEY-WORDS: TYPIC QUARTZIPSAMMENT; QUARTZIPSAMMENTIC HAPLORTOX; IMAZETAPHYR; HYDRAULIC CONDUCTIVITY; GROUNDWATER; HERBICIDE.

\section{REFERÊNCIAS}

1 BOUMA, J. Guide to the study of water movement in soil pedons above the water table. Madison: University of Wisconsin, Extension, 1973. 194 p.

2 CHE, M.; LOUX, M.M.; TRAINA, S.J.; LOGAN, T.J. Effects of $\mathrm{pH}$ on sorption and desorption of imazaquin and imazethapyr on clays and humic acid. Journal of Environmental Quality, v.21, p.698-703, 1992.

3 DORES, E.F.G.C.; DE-LAMONICA-FREIRE, E.M. Contaminação do ambiente aquático por pesticidas: estudo de caso águas usadas para consumo humano em Primavera do Leste, MT, análise preliminar. Química Nova, São Paulo, v.24, n.1, p. 27-36, 2001.

4 EMBRAPA. Centro Nacional de Pesquisa de Monitoramento e Avaliação de Impacto Ambiental. Uso agrícola das áreas de afloramento do Aqüífero Botucatu (Guarani) e implicações na qualidade da água subterrânea. Jaguariúna: Embrapa Meio Ambiente, 2002. 32 p. (Relatório final de projeto de pesquisa).

5 EMBRAPA. Centro Nacional de Pesquisa de Monitoramento e Avaliação de Impacto Ambiental. Manejo agro-ecológico das áreas de recarga do Aqüífero Guarani na região das nascentes do rio Araguaia, GO/MT. Jaguariúna: Embrapa Meio Ambiente, 2006. 38 p. (Relatório parcial de projeto de pesquisa). 
6 EMBRAPA. Centro Nacional de Pesquisa de Monitoramento e Avaliação de Impacto Ambiental. Manejo Agroecológico das áreas de recarga do Aqüífero Guarani na região das nascentes do rio Araguaia, GO/MT. Jaguariúna: Embrapa Meio Ambiente, 2007. 17 p. (Relatório final de projeto de pesquisa - subprojeto 03).

7 FERNANDES, B.; GALLOWAY, H.M.; BRONSON, R.D.; MANNERING, J.V. Condutividade hidráulica do solo saturado em três sistemas de manejo. Revista Ceres, Viçosa, v. 30, n.1, p. 232-241, 1983.

8 FERREIRA, J.A.; MARTIN-NETO, L.; VAZ, C.M.P.; REGITANO, J.B. Sorption interactions between imazaquin and a humic acid extracted from a typical Brazilian Oxisol. Journal of Environmental Quality, v. 31, p. 1665-1670, 2002.

9 GOETZ, A.J.; WEHTJE, G.; WALKER, R.H.; HAJEK, B. Soil solution and mobility characterization of imazaquin. Weed Science, v.34, p.788-793, 1986.

GOMES, F.P. Curso de estatística experimental. 11. ed. Piracicaba: Nobel, 1985. 466 p.

11 GOMES, M.A.F.; FILIZOLA, H.F.; SPADOTTO, C.A. Classificação das áreas de recarga do Sistema Aqüífero Guarani no Brasil em domínios pedomorfoagroclimáticos - subsídio aos estudos de avaliação de risco de contaminação das águas subterrâneas Revista do Departamento de Geogragia (USP), v. 18, p. 67-74, 2006.

12 GOMES, M.A.F.; SPADOTTO, C.A.; PEREIRA, A.S.; MATALLO, M.B.; LUCHINI, L.C. Movimento do herbicida tebutiuron em dois solos representativos das áreas de recarga do Aqǘf́fero Guarani. Revista Brasileira de Engenharia Agrícola e Ambiental, v. 10, n. 2, p. 479-483, 2006.

13 GOMES, M.A.F.; PAULA, Márcia Maria de.; DIOGO, A.; FARIAS, C.D.; FILIZOLA, H.F.; DORNELAS de SOUZA, M.; CARBALLAL, M.R. Levantamento pedológico das áreas de afloramento do Aqüífero Guarani na região das nascentes do rio Araguaia-GO/MT: subsídio aos estudos regionais de ordenamento agroambiental. In: GOMES, M.A.F. (ed.). Uso agrícola das áreas de afloramento do Aqüífero Guarani no Brasil: implicações para a água subterrânea e propostas de gestão com enfoque agroambiental. Jaguariúna: Embrapa Meio Ambiente, 2007. (cap. II, parte 2).

14 GREEN, R.E.; KARICKHOFF, S.W. Sorption estimates for modeling. In: CHENG, H.H. (Ed.). Pesticides in the soil environment: processes, impacts, and modeling. Madison: Soil Science Society of America, 1990. p. 79-101.

15 GUSTAFSON, D.I. Groundwater ubiquity score: a simple method for assessing pesticide leachability. Environmental Toxicology and Chemistry, v.8, n.4, p.339-357, 1989.

16 JARDIM. I.C.S.F.; MORAES, L.S.R.; QUEIROZ, S.C.N.; FERRACINI, V.L.; GOMES, M.A.F. Procedimentos analíticos e avaliação da presença de herbicidas em áreas de recarga do Aqüífero Guarani na região das nascentes do Rio Araguaia - MT/GO. In: GOMES, M.A.F. (ed.). Uso agrícola das áreas de afloramento do Aqüífero Guarani no Brasil - implicações para a água subterrânea e proposta de gestão com enfoque agroambiental. Brasília, DF: Embrapa Informação Tecnológica, 2008. Cap. 8, parte 2, p. 175-192.

17 LOUX, M.M.; LIEBL, R.A.; SLIFE, F.W. Adsorption of imazaquin and imazethapyr on soils, sediments, and selected adsorbents. Weed Science, v.37, p.712-718, 1989.

18 OUX, M.M.; REESE, K.D. Effect of soil pH on adsorption and persistence of imazaquin. Weed Science, v.40, p.490496, 1992.

19 MATALLO, M.B.; SPADOTTO, C.A.; LUCHINI, L.C.; GOMES, M.A.F. Sorption, degradation and leaching of tebuthiuron and diuron in soil columns. Journal of Environmental Science and Health, Fairfax, v. 40, p. 39-43, 2005

20 NICHOLLS, P.H. Organic contaminants in soils and ground water. In: JONES, K.C. (Ed.) Organic contaminants in the environment. London: Elsevier Applied Science, 1991. p.87-132.

21 OLIVEIRA, M.F. de. Retenção dos herbicidas flazasulfuron e imazaquin em solos de diferentes classes e hidrólise do flazasulfuron em diferentes valores de pH e temperatura. Campos dos Goytacazes, 1998. 71 p. Tese (Doutorado) - Universidade Estadual do Norte Fluminense.

22 REGITANO, J.B.; BISCHOFF, M.; LEE, L.S.; REICHERT, J.M.; TURCO, R.F. Retention of imazaquin in soil. Environmental Toxicology and Chemistry, v.16, p.397-404, 1997.

23 SPADOTTO, C.A. Screening method for assessing pesticide leaching potential. Pesticidas: revista de ecotoxicologia e meio ambiente, Curitiba, v.12, n.1, p.69-78. 2002.

24 SPADOTTO, C.A.; GOMES, M.A.F.; HORNSBY, A.G. Pesticide leaching potential assessment in multi-layered soils. Pesticidas: revista de ecotoxicologia e meio ambiente, Curitiba, v.12, n.1, p.1-13, 2002.

25 VIGNA, C.R.M.; MORAIS, L. S.R.; COLLINS, C.H.; JARDIM, I.C.S.F. Poly(Methyloctysiloxane) immobilized on silica as a sorbent for solid-phase extraction of some pesticides. J. Chromatogr. A, v. 1114, p. 211-215, 2006.

26 VonHERTWIG, K. Manual de herbicidas, desfolhantes, dessecantes e fitorreguladores. 2. ed. São Paulo: Editora Agronômica Ceres,1983. 480 p. 